\title{
METODOLOGIA DO ATENDIMENTO INTEGRADO Uma experiência de intervenção local ${ }^{1}$
}

\section{INTEGRATED CARE METHODOLOGY A local intervention experience}

\author{
Hélia Bracons \\ Universidade Lusófona de Humanidades e Tecnologias, Instituto de Serviço Social, Campo Grande 376, 1749-024 \\ Lisboa, Portugal. Email: helia.bracons@gmail.com
}

\begin{abstract}
Resumo: O presente artigo pretende dar a conhecer a metodologia do Atendimento Integrado e sua implementação no concelho de Loures, bem como refletir a forma como esta metodologia e a figura do gestor de caso tem assumido particular destaque nas práticas do Serviço Social, nomeadamente na metodologia referida.

Os dados empíricos utilizados foram retirados de entrevistas a "informantes privilegiados": os dois Coordenadores do Atendimento e Acompanhamento Social Integrado do Concelho. Ambos Assistentes Sociais.

O artigo conclui com uma breve reflexão sobre as potencialidades e constrangimentos da metodologia do Atendimento Integrado e aponta algumas reflexões e sugestões em torno destas questões para uma orientação prática e reflexiva do procedimento no atendimento e acompanhamento social integrado.
\end{abstract}

Palavras-chave: metodologia do Atendimento Integrado, Serviço Social, gestor de caso.

\begin{abstract}
This article presents the Integrated Care methodology and goes over its implementation in the municipality of Loures. It also discusses how this specific methodology and the case manager has assumed prominence in the practices of Social Services. The analysed data is based on interviews with "privileged informants": the two Coordinators of care and integrated Social Monitoring, both Social Workers. The article concludes with a brief discussion on the potentialities and constraints of the Integrated Care methodology and outlines some suggestions for its day-to day application.
\end{abstract}

Keywords: Integrated care methodology, Social Work, case manager.

\section{Breve contextualização sobre a metodologia do Atendimento Integrado}

A metodologia do Atendimento Integrado é atualmente uma prática desenvolvida pelos profissionais de Serviço Social com pessoas e públicos vulneráveis com o intuito de promover a sua capacitação, o empowerment e reforçar a autonomia e cidadania social.

A metodologia do Atendimento Integrado pretende intervir como principal resposta aos problemas sociais nas situações de pobreza e exclusão social, enaltecendo os direitos humanos e de cidadania, minimizando os problemas sociais, através de um trabalho de proximidade e do trabalho em rede. 
Como menciona Ferreira e Seno (2014, p. 349)

tendo como particular enfoque as pessoas, as relações humanas e o meio que os envolve, segue o pressuposto de que os problemas só se resolvem com a criação de condições para que a pessoa se autossuficiente ao nível dos recursos e consiga participar ativamente na vida em sociedade.

Esta metodologia enquadra-se na Agenda Social Europeia e nos apelos do Conselho Europeu e na Estratégia de Lisboa que traduzem preocupações constantes com os processos de inclusão social e coesão social, e com a identificação de princípios, objectivos e concentração, consequentemente com a eficácia das políticas sociais.

Este processo de racionalização leva a um conjunto de objectivos comuns, adoptados pelo Concelho Europeu de 2006, relativamente à protecção e inclusão social:

a) promoção da coesão social e igualdade de oportunidades;

b) interação com os objetivos de maior crescimento económico;

c) reforço da governação, transparência e participação dos agentes na conceção das políticas. (PNAI, 2006, p. 4)

A estratégia de inclusão social definida no PNAI 2006-2008 tem como principal finalidade, a inclusão de todos os cidadãos, garantindo o acesso aos recursos, aos direitos, aos bens e aos serviços, bem como promover a igualdade de oportunidades de participação social numa sociedade com melhor qualidade e coesão social (PNAI, 2006).

A metodologia de Atendimento Integrado foi considerada como uma boa prática social (PNAI, 2006) numa perspetiva de descentralização e desburocratização do atendimento, com vista ao aumento da capacidade de atendimento e acompanhamento social e respetiva otimização dos recursos.

Os objectivos principais desta metodologia são: "otimizar os recursos das entidades ao nível do atendimento e acompanhamento; diminuir o número de famílias que cada técnico acompanha; identificar e implementar um gestor de caso por família; e uniformizar os procedimentos organizativos e critérios de avaliação" (PNAI, 2006, p. 75, citado em Carvalho, 2009, p. 24).

Considerando esta metodologia emancipadora nas dinâmicas actuais de intervenção social, esta tem permitido

uma melhoria do funcionamento e articulação entre as organizações com responsabilidades no atendimento; $\mathrm{o}$ aumento significativo da capacidade no atendimento às famílias e indivíduos, devido à descentralização e desburocratização; maior eficácia e eficiência no atendimento e respostas aos problemas das famílias; e uma melhoria dos 
níveis de satisfação dos beneficiários quanto aos atendimentos e serviços prestados. (PNAI, 2006, citado em Carvalho, 2009, p. 24)

A metodologia de Atendimento Integrado vem, ainda, implementar um gestor de caso por família, permitindo um maior acompanhamento e uma proximidade das pessoas e suas situações e, possibilitando conhecer o agregado no seu todo. É importante ressaltar que olhar, reflectir e problematizar sobre este campo onde o Assistente Social está presente, torna-se imperativo e fundamental.

Como menciona Carvalho $(2009$, p. 26) “o profissional é considerado como o fio condutor em todo o processo de apoio à família e/ou indivíduo, no caso que se está a acompanhar".

O profissional é responsável pelo processo acompanhado, bem como da resposta ao problema e é também responsável pela articulação com as outras instituições e sistemas para uma resposta mais eficaz e adequada à verdadeira situação problema (Carvalho, 2009).

Para os referidos autores, este modelo, de gestão de casos é reconhecido como

estratégia inovadora em Serviço Social, utilizado para resolver problemas de eficácia e de acessibilidade e tendo com principal objectivo aumentar as potencialidades do acompanhamento social, cabendo ao gestor de caso acompanhar integralmente a pessoa ou a família, gerindo e mobilizando o trabalho em equipa. (Ferreira eSeno, 2014, p. 355)

Davis (citado em Ferreira e Seno, 2014, p. 355) "define a gestão de casos como uma abordagem centrada nos sujeitos e na coordenação de recursos".

Tal como menciona Amaro (2014, p. 107), “( ...) a figura do gestor de caso preconiza uma postura profissional sobretudo focalizada na apresentação dos resultados da sua prática, mais do que na resolução do problema do cliente. Concentra-se na gestão do processo e não na resolução do problema".

As críticas que recebeu este modelo de gestão de casos, estão com efeito relacionadas com "o binómio necessidade-recurso, e com a excessiva burocratização ligada à gestão, mais preocupada em cumprir com os critérios de qualidade e o ajustamento de orçamentos dos serviços, do que com a capacidade pessoal das pessoas" (Fernández e Romero, 2014, p. 252).

O Assistente Social assume um papel de elo de ligação na procura de soluções e estratégias tendo em vista o bem-estar da pessoa.

O Assistente Social nesta linha de pensamento é um profissional, mediador entre os recursos e as pessoas. Na verdade, esta dimensão centrada nos utentes e no domínio e aplicação de um conjunto de procedimentos e saberes para uma melhor resposta às situações, requer do profissional a capacidade de reflexão sobre as suas 
próprias práticas. Na perspetiva de Albuquerque (2011, p. 107) “a necessidade de agir, muitas vezes sob a pressão do momento, acentua a importância da capacidade reflexiva dos profissionais de Serviço Social como constitutiva da própria ação".

Ainda segundo a referida autora, a reflexividade implica características pessoais e profissionais do agente e o conhecimento do contexto, assumindo uma postura crítica, prospectiva e flexível (Albuquerque, 2011).

Os Assistentes Sociais, na sua prática quotidiana, encontram-se muitas vezes, sujeitos a exigências e solicitações por parte das organizações e também das populações com quem trabalham e, na verdade, necessitam de parar e reflectir sobre o que andam a fazer e como se devem posicionar face aos contextos onde se inserem.

Esta metodologia vem também possibilitar um trabalho mais próximo dos profissionais com os recursos da comunidade, estabelecendo as articulações e mediações necessárias, de acordo com as necessidades, mas também com as potencialidades dos indivíduos e famílias com quem está a intervir, intervindo assim de uma forma mais abrangente e holística.

Na linha de Davis (2008, citado em Ferreira e Seno, 2014, p. 349), "a visão holística do Serviço Social coloca os profissionais desta área numa posição favorável para intervir na área da desproteção social". Uma intervenção centrada no sujeito tendo em atenção a influência dos diferentes sistemas em que o sujeito se insere.

O Assistente Social é um articulador de mediações, no quotidiano das pessoas que procuram os seus serviços. Ele é um agente que trabalha com e nas mediações (Almeida, 2013). O seu posicionamento intermediário possibilita ao interlocutor ter visibilidade e cria condições para que a relação se estabeleça ou restabeleça entre as pessoas e a sociedade. "Criando espaços de troca de informação, fornecendo ou acedendo a nova informação, atribuindo recursos, providenciando serviços, encaminhando e mobilizando parcerias" (Almeida, 2013, p. 57).

O Assistente Social enquanto mediador e agente ativo na vida das pessoas, tem um papel fundamental na prevenção, na diminuição da conflitualidade e, acima de tudo, na criação de oportunidades de interação entre as pessoas entre si e com as organizações através da cooperação e da comunicação dialogante. Nesta medida, o trabalho em rede, em parceria e de cooperação ganha um novo enfoque e relevo.

Para Ferreira e Seno (2014, p. 353), a intervenção em rede ganha, um novo e diferente dinamismo na prática profissional

na medida em que obriga este a mudar o seu papel de responsável pela gestão dos problemas das pessoas ou da família e ser coordenador e gestor de recursos sociais de apoio e ajuda à pessoa e/ou família em necessidade, deixando a esta a responsabilidade individual do seu problema. 
Na perspectiva de Amaro (2008) é necessário que os Assistentes Sociais pugnem por uma postura profissional orientada pelos valores da profissão, como o da participação das populações, do empowerment, da criatividade, entre outros, e assim comprometerem-se com as populações no desenvolvimento das suas potencialidades. O chamado paradigma alternativo. O profissional, neste contexto, está vinculado com as populações mais desfavorecidas e vulneráveis que deverá trabalhar no sentido de as mobilizar, capacitar e consciencializar das suas potencialidades e constrangimentos fornecendo-lhes ferramentas de auxílio para que se sintam mais integradas (Amaro, 2008).

Na linha de pensamento da autora Almeida (2013, p. 41)

a gestão de caso constitui uma estratégia pois enquadra um conjunto de meios - fins orientados para o equilíbrio ou para a mudança individual ou familiar, tendo como meta, o bem estar do utente, mas é igualmente um processo de intervenção e gestão ancorada na participação, na articulação de serviços, na intervenção em rede e em equipa, um modelo centrado nas pessoas (...) onde a coordenação colaborativa e a comunicação ocupam um lugar de destaque.

E o profissional "ao promover a participação na construção de soluções satisfatórias, promove simultaneamente a aprendizagem da cooperação, a construção dos laços sociais e a coesão social"' (Costa e Silva et al., 2016, p. 12).

\section{A metodologia do Atendimento Integrado no concelho de Loures}

A metodologia do Atendimento Integrado no concelho de Loures surge, inicialmente, no âmbito da Comissão Social de freguesia de Santo António dos Cavaleiros, da Rede Social do Concelho de Loures; iniciou em Março de 2005 como projecto-piloto na freguesia, sendo o Protocolo assinado a 3 de Outubro de 2007.

Os principais problemas identificados pela freguesia foram: a peregrinação dos indivíduos/famílias aos diversos serviços; os diferentes diagnósticos sociais; a sobreposição e duplicação de intervenções; o desgaste e duplicação de recursos; a dificuldade de articulação entre as entidades e a morosidade de respostas.

A implementação desta metodologia teve como principais objectivos: evitar as respostas fragmentadas e a duplicação de intervenções junto do mesmo indivíduo/família; respeitar a individualidade do utente, dando uma resposta global ás suas necessidades; organizar e rentabilizar os recursos existentes, diminuindo a morosidade das respostas; aproximar os serviços de atendimento à população; promover a estreita articulação entre instituições e qualificar a intervenção.

Neste contexto, a população alvo era a população residente na freguesia de 
Santo António dos Cavaleiros, tendo como entidades parceiras, cinco entidades formais, sendo quatro organizações estatais e uma organização particular de solidariedade social e uma entidade informal (Protocolo do Atendimento Integrado da freguesia de Santo António dos Cavaleiros, 2007). ${ }^{2}$

Mais tarde, no âmbito da Rede Social do Concelho de Loures e com base nas necessidades identificadas pelos Parceiros relativamente a uma intervenção em proximidade mais eficaz e qualificada, foi aprovado em fevereiro de 2011 pelo Conselho Local de Acção Social de Loures o modelo de funcionamento do serviço de atendimento e acompanhamento social integrado (Protocolo de parceria no âmbito do serviço de atendimento e acompanhamento integrado do concelho de Loures assinado no dia 11 de Maio de 2012 pelas entidades signatárias).

O Serviço de Atendimento e Acompanhamento Social Integrado (SAASI) visa qualificar o atendimento social e o trabalho de parceria com vista a uma resposta mais eficaz e eficiente às solicitações das populações. Este serviço rege-se pelos princípios do trabalho em parceria, territorialização da intervenção e participação de todos os intervenientes e centra-se no indivíduo, na família e na comunidade, otimizando os resultados da intervenção social e rentabilizando os recursos disponíveis.

O atendimento e acompanhamento social, enquanto medida de política social, constitui-se num espaço privilegiado de manifestação e interpretação diagnóstica das necessidades e dos problemas da população os quais exigem uma intervenção continuada e global.

Breve apresentação e análise dos dados a partir das vozes dos Coordenadores do Atendimento Integrado

O presente trabalho enquadra-se num estudo mais alargado. Trata-se de um trabalho empírico desenvolvido no âmbito da tese de doutoramento em Serviço Social. Optou-se por uma metodologia qualitativa e a técnica utilizada para a obtenção de dados junto dos participantes, foi a entrevista semiestruturada. Esta é caracterizada "pelo emprego de uma lista de perguntas ordenadas e redigidas por igual para os entrevistados, mas de resposta livre ou aberta" (Moreira, 2007, p. 206).

Os dados empíricos utilizados foram retirados de entrevistas a "informantes privilegiados": os dois Coordenadores do Atendimento e Acompanhamento Social Integrado do Concelho (da Segurança Social e da Camara Municipal de Loures). Ambos Assistentes Sociais. Delineamos como objectivos compreender quais os propósitos que estiveram na base da implementação do Serviço Atendimento Integrado em Loures e conhecer o seu funcionamento; perceber os princípios orientadores da metodologia e reflectir como a figura do gestor de caso tem assumido 
destaque nas práticas do Serviço Social, particularmente na metodologia de Atendimento Integrado.

Os dados recolhidos foram analisados através da análise de conteúdo que segundo Guerra (2006, p. 62), "tem uma dimensão descritiva que visa dar conta do que nos foi narrado e uma dimensão interpretativa que decorre das interrogações do analista face ao objeto de estudo".

Na perspetiva do Coordenador do AI da Segurança Social de Loures, os objectivos que estiveram na base da implementação do SAASI em Loures foram:

Maior rentabilização dos recursos humanos com intervenção social no Concelho; aumento da capacidade de resposta a um maior número de utentes; diminuição da morosidade das respostas; diminuição/inexistência de duplicidade de intervenção; maior capacidade de resposta aos problemas dos indivíduos e famílias em tempo útil e uma concepção mais ampla da Acção Social, todos os serviços e instituições da comunidade assumem a responsabilidade na intervenção social (Coord. AI da SSL).

Os Coordenadoras do AI do concelho de Loures referem que o modelo de funcionamento do SAI foi integrado em Loures em fevereiro de 2011, tendo surgido na freguesia de Santo António dos Cavaleiros em 2007 e só mais tarde iniciou-se o atendimento/acompanhamento nas 18 freguesias do Concelho.

O Atendimento Integrado surgiu na freguesia de Santo António dos Cavaleiros em 2007 e foi alargado às restantes freguesias em abril de 2011 (Coord. AI da CML).

O modelo de funcionamento do Serviço de Atendimento e Acompanhamento Social Integrado no Concelho de Loures SAASIL foi aprovado em fevereiro de 2011 pelo Concelho Local de Acção Social de Loures e no dia 01 de abril do mesmo ano iniciou-se o atendimento/acompanhamento nas 18 Freguesias (Coord. AI da SSL).

$\mathrm{O}$ atendimento e acompanhamento social integram um conjunto de procedimentos que se traduzem em quatro fases distintas: acolhimento/atendimento; contratualização; acompanhamento social e avaliação da intervenção.

Os princípios orientadores da metodologia de Atendimento Integrado devem ser coincidentes com os princípios gerais do atendimento e acompanhamento social preconizados pelo Manual de Procedimentos para o Atendimento e Acompanhamento Social do Instituto Segurança Social, nomeadamente na promoção da inserção social e comunitária dos indivíduos e famílias; contratualização, através da definição de um plano de inserção como instrumento mobilizador da co-responsabilização dos indivíduos e dos serviços; personalização, selectividade e flexibilidade dos apoios sociais; intervenção prioritária das entidades 
mais próximas dos cidadãos e, valorização das parcerias, no âmbito da rede social para uma actuação integrada junto dos indivíduos e famílias.

Na leitura dos princípios que regem esta metodologia, pressupõe-se que a intervenção social está cada vez mais confinada ao estabelecimento de um contrato e de uma negociação do profissional com o utente. Isto levanta alguns aspectos que devem ser pensados e repensados na medida em que a prática tende a tornar-se mais instrumental e mais preocupada com os resultados do que com os processos.

Como referem Branco e Amaro (2011, p. 662) “os Assistentes Sociais hoje dirigem a sua atenção para a apreciação do posicionamento dos indivíduos perante a adesão ao contrato e a apresentação dos resultados".

Na óptica do Coordenadora do AI da Segurança Social, a metodologia do AI centra-se no indivíduo, na família e na comunidade. O gestor de caso tem como prioridade na sua intervenção a pessoa no seu todo, tendo como objectivo estabelecer uma relação de proximidade e uma relação empática que permita acompanhar todo o processo de intervenção e de avaliação da pessoa e sua família. A proximidade do profissional com a pessoa permite um conhecimento aprofundado sobre as vivências, problemas, expectativas e potencialidades do outro. Os profissionais priorizam ainda a utilização e dinamização dos recursos da comunidade para a resolução das situações/problema.

Esta metodologia centra-se no indivíduo, na família e na comunidade, priorizando a utilização dos recursos existentes na Comunidade.

É ao gestor do caso a quem cabe estabelecer uma relação empática e de confiança, que lhe vai permitir acompanhar todo o processo de avaliação e acompanhamento da família e coordenar a sua coordenação com os parceiros que for necessário envolver para a resolução da situação.

A proximidade técnico-família, família-técnico, permite um conhecimento do quotidiano da família, dos seus costumes, hábitos, interesses e expectativas. Esta "relação" habilita o gestor do caso com um conhecimento da família do ponto de vista individual e por outro lado, da comunidade (Coord. AI da SSL).

Para Ferreira e Seno (2014), o gestor de caso tem a função de gerir e mobilizar de forma coordenada o trabalho de equipa entre diferentes técnicos e instituições, mobilizando recursos e respostas através da articulação com outras instituições e serviços.

Como já mencionado, uma das grandes mais-valias do modelo deSAASI é assumir-se como uma ferramenta de empowerment e de capacitação dos indivíduos e famílias e, enquanto factor de inovação das medidas de política social, na medida 
em que fomenta um conhecimento aprofundado da realidade, consolida o trabalho em rede e qualifica as instituições que actuam na área social, através da formação contínua dos técnicos.

Para Pinto (2013, p. 51)

o empowerment é um processo de transformação através da ação, através do qual cada sujeito se torna parte verdadeiramente participante do seu destino individual e da comunidade de que faz parte, o que implica um trabalho, quer sobre si mesmo quer com os outros.

No estudo desenvolvido por Ferreira e Seno (2014, p. 351), destaca-se o papel do gestor de caso "como facilitador do processo de capacitação e empowerment, potenciando o processo de mudança nos sujeitos de atenção social".

Como já referido, a base da intervenção assenta na figura do gestor de caso, definido através da identificação da problemática dominante, na sequência de um diagnóstico compreensivo e fundamentado da situação. O gestor de caso acompanha todo o processo e coordena a sua atuação com os parceiros para a resolução da situação e evitando assim a duplicação de intervenções.

Como refere um dos Coordenadores, o AI surge com a preocupação de acabar com a intervenção de vários técnicos numa só pessoa/família e sua situação. Ou seja, havendo a figura de gestor de caso evita assim, duplicação de intervenções. O trabalho de articulação com os serviços da comunidade é também mencionado pelo profissional coordenador.

Surgiu da necessidade de acabar com a intervenção de vários técnicos, criando-se um gestor de caso que trabalha o agregado no seu todo, articulando com vários serviços da comunidade, sempre que necessário. Foi criado ainda para acabar com a lista de espera existente e que a Segurança Social não conseguia dar resposta (Coord. AI da CML).

O modelo tem como requisitos o trabalho em rede e uma forte coordenação entre as várias instituições com intervenção social local e pressupõe que são as necessidades das pessoas o centro da intervenção, conjugando-se sinergias e recursos.

Não perspectiva do Coordenador do AI da CML, a metodologia do AI, sendo um serviço de proximidade, não permite um conhecimento aprofundado das especificidades culturais das pessoas e dos grupos. Esta metodologia centra-se no indivíduo e sua família, sendo uma intervenção direccionada para o caso. Refere ainda que o trabalho em parceria é fundamental para uma intervenção mais direccionada de acordo com as problemáticas apresentadas pelas pessoas. 
O AI é um serviço de proximidade. Não permite um conhecimento aprofundado dos grupos culturais porque trabalha no âmbito do serviço social de casos e não de grupos.

O AI só funciona se as parcerias forem mesmo parceiras na intervenção. Existem algumas dificuldades quando algumas instituições locais, onde inicialmente se procura uma resposta adequada ao problema apresentado pelo utente, não confia no AI, duplicando a intervenção e algumas vezes fazendo diagnósticos diferentes (Coord. AI da CML).

O SAASIL funciona com as seguintes estruturas operativas: com as equipas de atendimento/acompanhamento social constituídas por técnicos superiores de serviço social e de psicologia, designados como gestores de caso; equipa de apoio técnico; equipa de coordenação e pelo conselho de parceiros, que integra um representante, com poder de decisão, de cada Entidade.

$\mathrm{O}$ atendimento é feito pelo técnico designado para o efeito, que assume as funções de gestor de caso que compete assegurar o acompanhamento do Plano de Inserção da família e coordenar o processo com os restantes parceiros.

Semanalmente, realizam-se reuniões de equipa para os técnicos apresentarem o pré-diagnóstico dos processos, assim como são designados os gestores de caso nas situações em que não tenha sido atribuído. A equipa de coordenação reúne mensalmente.

No Manual Geral de Procedimentos do Serviço de Atendimento e Acompanhamento Integrado do concelho de Loures consta que os técnicos, no exercício da sua actividade profissional, deverão pautar-se por uma conduta responsável e ética; salvaguardar os valores fundamentais da dignidade humana; assegurar os princípios de privacidade e confidencialidade e colaborar com os indivíduos e famílias, na defesa do seu próprio interesse e no interesse dos outros com eles envolvidos (Manual Geral de Procedimentos do Serviço de Atendimento e Acompanhamento Integrado do Concelho de Loures, Fevereiro de 2011). ${ }^{3}$

Os profissionais do SAASIL são Assistentes Sociais de instituições do Concelho que disponibilizaram alguns técnicos para integrarem neste Projecto.

Todos os técnicos do AI são assistentes sociais. A Autarquia disponibilizou 13 técnicos para este serviço e as instituições e juntas de freguesia que tinham técnicos daquela área e que assim o entenderam, também disponibilizaram esses técnicos (Coord. AI CML).

De forma a garantir a eficiência e eficácia na implementação do SAAASIL, anteriormente ao seu início foi feito um levantamento das instituições com intervenção no Concelho bem como avaliando a motivação, expectativas e constrangimentos destas. Nesta conformidade foram incluídos todos os técnicos de Serviço 
Social cujas entidades disponibilizaram para integrarem este projecto (Coord. AI da SSL).

Os técnicos gestores de casos são provenientes das seguintes organizações:

- Câmara Municipal de Loures; Junta de Freguesia de São Julião do Tojal; Junta de Freguesia de Santo António dos Cavaleiros; Junta de Freguesia de Moscavide; Junta de Freguesia de São João da Talha; Junta de Freguesia de Santa Iria da Azoia; Associação Luís Pereira da Mota; Centro Cultural e Social de Santo António dos Cavaleiros e Santa Cada da Misericórdia de Loures (Coord. AI da SSL).

- Quando se questiona o Coordenador do AI sobre as sugestões que propõe para que o AI permita ser um serviço de maior proximidade e mais eficaz no trabalho com populações diferenciadas culturalmente, o profissional refere que o elevado número de casos por técnico para acompanhamento não permite um contacto próximo e não permite desenvolver um trabalho que vá ao encontro das especificidades e singularidades das populações diversificadas que recorrem ao AI.

Diminuição do número de casos em acompanhamento por cada gestor de caso. $\mathrm{O}$ elevado número de casos em acompanhamento pelos gestores de caso, muitas vezes não permite o acompanhamento sistemático e de proximidade que se pretende com esta metodologia, só com a definição de um limite máximo de situação em acompanhamento por gestor de caso se poderá desenvolver um trabalho ainda mais eficaz e que responda às especificidades e singularidades de uma população tão diversificada e heterogenia (Coord. AI da SSL).

Na intervenção social com pessoas e famílias com especificidades culturais diversificadas, "os profissionais deverão conhecer as características principais dos grupos culturais, suas especificidades e vulnerabilidades, bem como alguns aspectos da sua organização enquanto grupo" (Bracons e Rosalina, 2015, p. 236). Isto permitirá uma intervenção mais integrada, implicando novos desafios, novos conhecimentos, habilidades e competências dos Assistentes Sociais.

Como já anteriormente referido, uma das preocupações que se verifica é o aumento significativo de casos, por profissional, para acompanhar, o que tem conduzido gradualmente a uma intervenção profissional com preocupações mais administrativas, procedimentais e managerialistas. A este propósito, Branco e Amaro (2011, p. 666) referem que “(...) a intervenção em Serviço Social torna-se cada vez mais burocrática e managerialista e cada vez menos relacional e política". 
Como se verifica neste testemunho do profissional Coordenador, esta preocupação está presente nas práticas dos Assistentes Sociais do AI, pois estes profissionais, para além de acompanharem muitos casos, com problemáticas diversas e complexas, têm ainda que informatizar os dados semanalmente, acompanhar de perto as famílias e irem controlando as situações recorrendo a uma fase de avaliação-diagnóstico centrada sobretudo nos resultados da acção das situações dos utentes. Estamos perante uma lógica de demonstração de resultados e quase que, $\mathrm{o}$ estabelecimento de uma proximidade maior, a criação de uma relação empática, o conhecer ao pormenor certas características culturais e religiosas (dimensões também igualmente importantes) tende a ser mais escassa.

\section{Considerações finais}

A reflexão sobre a metodologia do Atendimento Integrado na prática profissional do Assistente Social constitui um debate em aberto e em permanente construção. $\mathrm{O}$ objectivo do presente artigo foi levantar um pouco o véu relativo a algumas potencialidades e constrangimentos desta intervenção e, poder assim, contribuir com algumas sugestões para uma prática mais reflexiva na intervenção dos profissionais de Serviço Social.

De acordo com os resultados dos estudos de Carvalho (2009) e Ferreira e Seno (2014), e dos testemunhos dos profissionais Coordenadores (Bracons, 2017) os aspectos positivos que podemos realçar, é que a metodologia do Atendimento Integrado tem impacto nas pessoas; o profissional aciona recursos da comunidade, evitando a duplicação de intervenções; o trabalho em rede e em parceria é evidenciado e fundamental e contribui para o processo de capacitação e empowerment do sujeito.

Quanto às dimensões menos positivas, é referido que nem todas as instituições estão preparadas para a intervenção em rede; o aumento significativo do número de processos por gestor de caso limita a proximidade desejável no acompanhamento aos indivíduos e famílias; a informatização dos dados semanalmente, numa única base de dados (Seg. Social) limita e é um constrangimento para os profissionais.

A título de conclusão, considera-se particularmente relevante estudar a perspectiva das pessoas e famílias acompanhadas, quanto à operacionalização desta metodologia; analisar o impacto da intervenção em rede e perceber os mecanismos de racionalização de recursos; identificar os constrangimentos dos Assistentes Sociais quanto às decisões tomadas e quanto ao plano de intervenção adequado a cada pessoa/família de acordo com as suas especificidades e complexidades; compreender se esta metodologia evidencia os princípios e valores da profissão; verificar se uma 
intervenção mais focalizada e centrada nos sujeitos limita a capacidade de um trabalho mais abrangente, mais sistémico e mais comunitário; reflectir e questionar os conceitos de atendimento e acompanhamento integrado com os profissionais que integram esta metodologia e identificar as necessidades destes profissionais, enquanto protagonistas e actores da intervenção, que têm em mãos a vida de muitos indivíduos.

Em suma, uma intervenção que promove o bem-estar das pessoas, numa óptica de desenvolvimento pessoal das mesmas, requer cada vez mais, um Assistente Social informado, conhecedor dos contextos, proactivo, curioso, entusiasta, apaixonado e um profissional reflexivo, que saiba reflectir e questionar a sua prática, para, assim, poder avaliar e propor novas formas e estratégias de actuação, sem perder de vista os valores do Serviço Social.

\section{Notas}

1 Este artigo resulta de uma comunicação que foi apresentada, em 19 de abril de 2017, pela autora, no Encontro Sociologia e Intervenção Social organizado pela Associação Portuguesa de Sociologia.

Os dados recolhidos resultam da investigação efetuada no âmbito do doutoramento em Serviço Social.

2 Documento não publicado.

3 Documento não publicado.

Por decisão pessoal, a autora do texto escreve segundo o antigo acordo ortográfico.

\section{Referências}

Albuquerque, C. P. (2011). Legitimidade e reconhecimento da prática de Serviço Social. Abordagem construtivista. Serviço Social em Revista, 13(2), 104-118.

Almeida, H. (2013). Gestão de caso e mediação social: Abordagens, processos e competências cruzadas na agenda do conhecimento em Serviço Social. In C. Santos, C. Albuquerque, e H. Almeida (Eds.), Serviço Social, mutações e desafios. (pp. 15-63). Coimbra: Imprensa da Universidade de Coimbra.

Amaro, M. I. (2008). Os campos paradigmáticos do Serviço Social: Proposta para uma categorização das teorias em presença. Locus Soci@l, (1), 65-80.

Amaro, M. I. (2014). Um admirável mundo novo? Tecnologia e intervenção na contemporaneidade. In M. I. Carvalho, e C. Pinto (Eds.), Serviço Social, teorias e práticas (pp. 97-111). Lisboa: Pactor.

Bracons, H. (2017). Conhecer para intervir: Competência cultural no Serviço Social (Tese de doutoramento, Universidade Católica Portuguesa). 
Bracons, H., e R., A. (2015). Serviço Social com famílias imigrantes. In M. I. Carvalho (Ed.), Serviço Social com famílias (pp. 225-237). Lisboa: Pactor.

Branco, F., e Amaro, M. I. (2011). As práticas do "Serviço Social activo" no âmbito das novas tendências da política social: uma perspectiva portuguesa. Serviço Social e Sociedade, (108), 656-679.

Carvalho, A. F. (2009). Serviço Social e metodologia do atendimento integrado (Tese de mestrado), ISCTE, Lisboa.

Costa e Silva, Ana, et al. (2016). Mediação intercultural e território: Estratégias e desafios. In Alto Comissariado para as Migrações, I.P. (Ed.), Entre iguais e diferentes: A mediação intercultural. Atas das I Jornadas da Rede de Ensino Superior para a Mediação Intercultural Alto Comissariado para as Migrações, I.P (pp. 9-29). Lisboa, ACM, I.P.

Fernández, T., e Romero, L. (2014). Fundamentos teóricos do Serviço Social individualizado. In M. I. Carvalho e C. Pinto (Eds.), Serviço Social, teorias e práticas (pp. 243-257). Lisboa: Pactor.

Ferreira, J., e Seno, P. (2014). Atendimento e acompanhamento integrado: Uma prática do Serviço Social. In M. I. Carvalho, e C. Pinto (Eds.), Serviço Social, teorias e práticas (pp. 347-366). Lisboa: Pactor.

Guerra, I. (2006). Pesquisa qualitativa e análise de conteúdo - Sentidos e formas de uso. Estoril: Principia.

Moreira, C. D. (2007). Teorias e práticas de investigação. Lisboa: Universidade Técnica de Lisboa, ISCSP.

Pinto, C. (2013), Uma prática de empowerment com adultos idosos. In M. I. Carvalho (Ed.), Serviço Social no envelhecimento (pp. 49-65). Lisboa: Pactor.

PNAI. (2006). Plano Nacional de Acção para a Inclusão 2006-2008. Lisboa: Ministério do Trabalho e da Solidariedade Social.

Hélia Bracons. Universidade Lusófona de Humanidades e Tecnologias, Instituto de Serviço Social. Email: helia.bracons@gmail.com

Data de submissão: 01/05/2017 | Data de aceitação: 11/09/2017 